This item was submitted to Loughborough's Research Repository by the author.

Items in Figshare are protected by copyright, with all rights reserved, unless otherwise indicated.

\title{
Deriving on-road spatial vehicle emission profiles from chassis dynamometer
} experiments

\section{PLEASE CITE THE PUBLISHED VERSION}

\section{PUBLISHER}

Professional Engineering Publishing / @ IMECHE

\section{VERSION}

VoR (Version of Record)

\section{LICENCE}

CC BY-NC-ND 4.0

\section{REPOSITORY RECORD}

Samuel, S., D. Morrey, Colin P. Garner, D.H.C. Taylor, Mark Fowkes, and L. Austin. 2019. "Deriving On-road Spatial Vehicle Emission Profiles from Chassis Dynamometer Experiments". figshare. https://hdl.handle.net/2134/4834. 
This item was submitted to Loughborough's Institutional Repository (https://dspace.lboro.ac.uk/) by the author and is made available under the following Creative Commons Licence conditions.

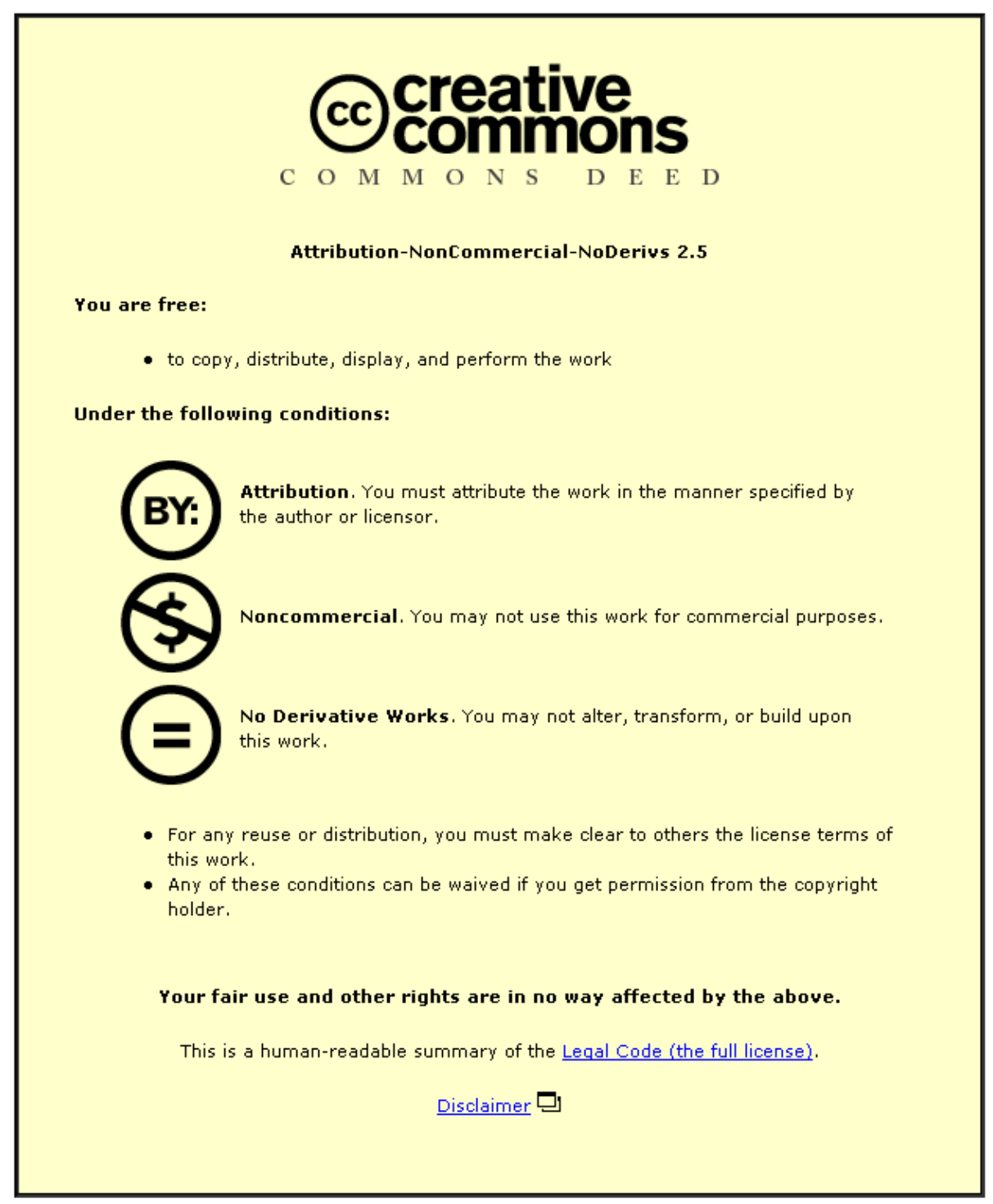

For the full text of this licence, please go to: http://creativecommons.org/licenses/by-nc-nd/2.5/ 


\title{
Deriving on-road spatial vehicle emission profiles from chassis dynamometer experiments
}

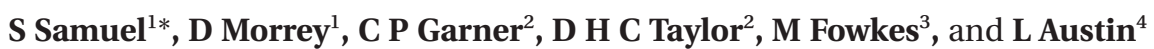 \\ ${ }^{1}$ Oxford Brookes University, Oxford, UK \\ ${ }^{2}$ Loughborough University, Loughborough, UK \\ ${ }^{3}$ MIRA, UK \\ ${ }^{4}$ University of Surrey, Guildford, UK
}

The manuscript was received on 8 September 2004 and was accepted after revision for publication on 24 August 2005.

DOI: $10.1243 / 095440705 X 69678$

\begin{abstract}
A method has been derived for the identification of spatial emission hot-spots on vehicle road routes using chassis dynamometer data. The work presented here uses tailpipeout carbon monoxide (CO) levels to demonstrate the application of the method. The approach is used to analyse critically methods used by legislators that derive road-side emission levels from the vehicle emission inventory and legislative emission levels. The work presented in this paper demonstrates that the generic approach using vehicle speed, gear change patterns, spatial geographical data, and route geometric information is sufficient for the identification of the location of emission hot-spots in any journey route of interest.
\end{abstract}

Keywords: emission hot-spots, spatial emission distribution, real-world emission levels

\section{INTRODUCTION}

One of the main aims and applications of chassis dynamometer tests is to replicate the actual drive cycle of the vehicle journey route in terms of vehicle speed against time. The exhaust emissions generated for the specified drive cycle using a vehicle speed versus time trace on a chassis dynamometer represent the tailpipe-out emission levels for a given route. The amount of emissions produced at every instant can vary to a large extent over the duration of a journey and this depends upon the nature of driving, traffic conditions, road network, and road geometry. In addition, highly localized emission levels (often referred to as 'hot-spots') can be created in a few geographic locations along the route, and cause considerable damage to the environment in some sections of the journey while leaving the rest of the route largely unaffected.

Legislative limits on tailpipe-out emission levels give most significance to the weighted emissions in $\mathrm{g} / \mathrm{km}$ produced for a specified test drive cycle. The

\footnotetext{
* Corresponding author: School of Technology, Oxford Brookes University, Gipsy Lane Campus, Headington, Oxford OX3 OBP, UK.email:s.samuel@brookes.ac.uk
}

weighted emission values for a specified test drive cycle are measured using constant volume sampling (CVS) bag methods. The weighted emission approach normalizes the emission levels over the duration of the complete journey and neglects the importance of localized emission hot-spots. Hence, this paper derives a method and demonstrates the application of using chassis dynamometer data to predict the spatial distribution of exhaust emissions over the duration of the journey and to identify the location of localized emission hot-spots in the journey route. This has significant value for road network planners who wish to minimize the impact of vehicle exhaust emissions on the environment.

\section{BACKGROUND}

Road traffic is the dominant source of carbon monoxide (CO) emissions in urban areas in the United Kingdom, typically contributing more than 90 per cent [1] of total emissions. The CO concentration is, therefore, likely to be highest at or near the roadside. There are two main approaches followed by various researchers and regulatory authorities to estimate and forecast roadside CO concentrations. 
The method followed by the UK Department for Environment, Food and Rural Affairs (DEFRA) uses the National Atmospheric Emission Inventory (NAEI) [2] and data from the roadside monitoring sites [1] within the United Kingdom. Future forecasts are made based on linear extrapolation of these data by the Department of Environment, Transport and the Regions (DETR).

The second main method of prediction of roadside CO or other emission species involves simulation techniques [3-6]. For applying this method, information on the traffic flow characteristics within the road network of interest must be available to characterize emissions from motor vehicles at particular locations on the route. This method of prediction requires traffic flow simulation models, pollution dispersion models, and roadside measurement monitoring for the validation of the methodology. Once these models and the methodology are validated they can be used for the forecast of roadside CO levels.

However, both of these existing techniques have inherent disadvantages. The DETR technique uses the statistics of vehicles in the United Kingdom and the legislative emission values for estimation of the traffic related emission inventory. These legislative values have been found to be significantly lower than the real-world emission levels [7]. In addition, errors originating from the prediction of the traffic related pollution using a linear extrapolation technique are significantly high.

The simulation techniques based on pollution dispersion models employ traffic flow simulation models. These traffic flow simulation models can be divided into two general classes as macroscopic and microscopic models. The macroscopic models, e.g. TRANSYT-7F, TRAF, FREQ, etc. $[\mathbf{8}, \mathbf{9}]$, are based on deterministic relationships between road type, interaction characteristics, and the traffic flow. The microscopic models, e.g. VISSIM, CORSIM, FLOWSIM, INTEGRATION, Paramics, SIDRA, Syncro/Sim Traffic, etc. [9-11], simulate the movement of individual vehicles through the network being modelled. In either type of model, emission levels are estimated based on vehicle speed and acceleration characteristics. The work of Samuel et al. [12], however, has identified that vehicle speed and acceleration levels are not the most significant parameters that determine the levels of tailpipe-out emissions. They found that the engine performance map has two distinct zones: one a clean zone to meet the legislative limits and the other an unclean zone, outside the boundary of the legislative performance envelope. Similar observations have been reported in recent years by Kleeman [13] and Kågeson [14]. When the vehicle operating points remain inside the clean zone of the engine performance map, the emission levels are low and within legislative limits irrespective of vehicle speed and acceleration. However, when the vehicle operating points move into the unclean zone of the engine performance map, tailpipe-out emission levels will be significantly higher than the legislative limits. Hence, the characteristics of the engine performance map are the critical factors that determine the levels of real-world emission levels of a particular vehicle.

Finally, the traffic flow models that are unable to model the behaviour of different drivers (psychophysical) may not predict the realistic driving behaviour [11] of the drivers. A model like VISSIM $[4,11]$, which is based on a psychophysical car following model, requires a significant amount of experimental data for its calibration.

The work of Park et al. [4], which used a MODEM data base to establish a speed-based emission database, a VISSIM model for stochastic microscopic traffic flow simulation, and a Gaussian-based dispersion model for pollution dispersion studies, underestimated roadside emission levels for the Kent area. One of the main reasons for the underestimation was identified as poor representation of the real-world driving pattern. Hence, a realistic estimation of spatial emission distribution needs a real-world drive cycle and an accurate measurement of on-road vehicle emission levels [15-17]. The data obtained from on-road measurements can be used as an input to the pollution dispersion model. However, on-road measurement is expensive considering the number of the vehicles that are needed to represent the spectrum of the vehicles driven on one particular route. Hence, the present work has sought to derive a systematic approach to obtain spatial emission profiles using chassis dynamometer data.

The present work focuses on tailpipe CO mainly based on the following:

1. The previous work of the present authors reported in reference [18] identified that $\mathrm{CO}$ is the most affected emission species during real-world driving in the United Kingdom for a typical light-duty, EURO-IV certified gasoline powered vehicle. That work used four different types of drive cycles representing passive, intermediate, and aggressive drive cycles and another drive cycle, Harsh-MIRA drive cycle, which is the maximum driving performance possible with the given vehicle. The results for tailpipe $\mathrm{CO}$ from that study have been reproduced from reference [18] to add clarity to the content of this paper and are shown in Fig. 1. The details about different drive cycles can also be found in references [18] and [19]. 


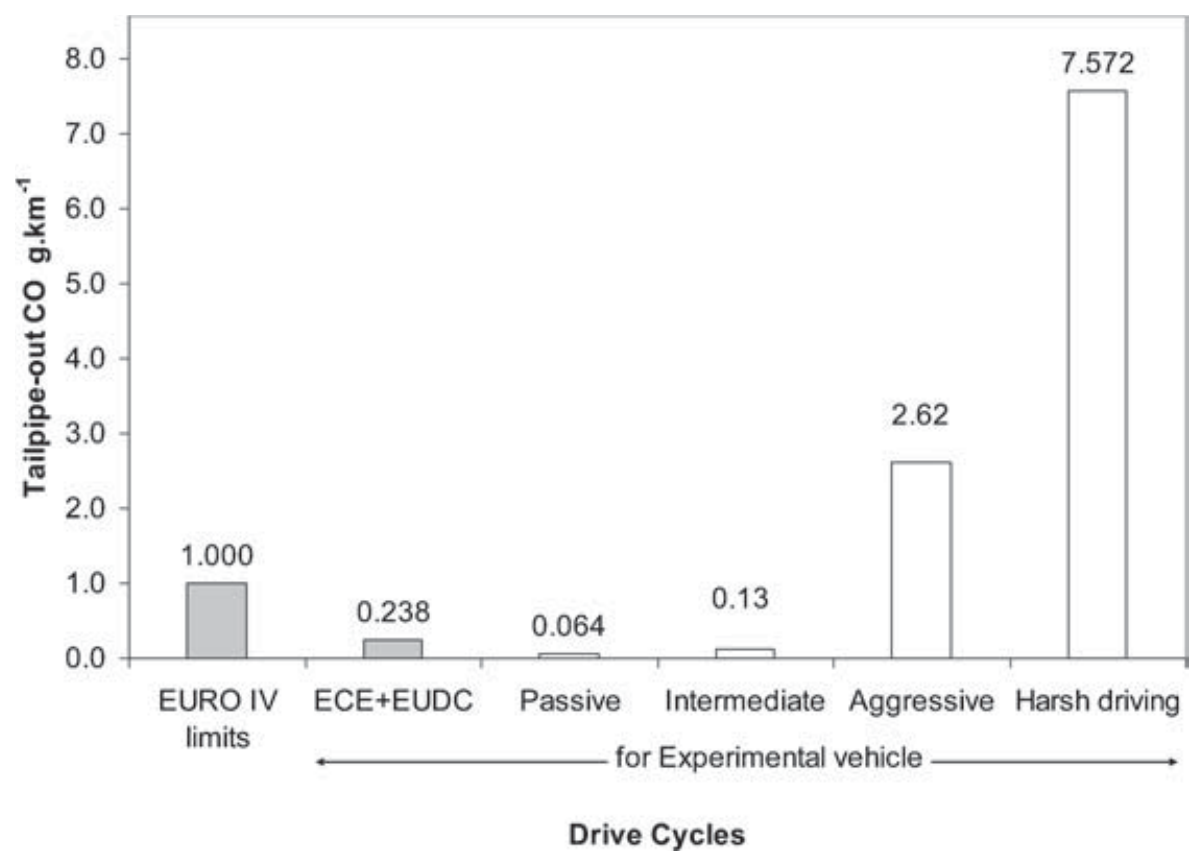

Fig. 1 Tailpipe CO levels from a typical EURO-IV vehicle when tested using different drive cycles. (Reproduced from reference [18])

2. Most of the fixed-site emission monitoring stations in the United Kingdom [20] measure ambient CO concentrations. It has been identified by various researchers that the levels measured by fixed-site monitoring stations significantly underestimate the real-world pollution levels inside the vehicle [21-23]. This suggests that it is difficult to use emission levels measured by fixed-site monitoring stations for pollution levels close to the traffic lane in most of the places unless a fixedsite station is actually placed near the area of concern.

3. Finally, CO is colourless, odourless unlike unburned hydrocarbons. Hence a cyclist or pedestrian in the vicinity of the traffic lane would find it difficult to detect its presence without the aid of any instruments. In addition, the concentration levels of tailpipe unburned hydrocarbon and $\mathrm{NO}_{x}$ are significantly lower than that of tailpipe CO [18] levels for given real-world driving scenarios.

\section{GEOGRAPHICAL FACTORS AND SPATIAL EMISSION LEVELS}

Actual vehicle driving routes consist of different road sections that are straight, those that have vertical gradients (for drainage or due to landscape), those with horizontal curvature due to roundabouts and traffic islands (as shown in Fig. 2), and roads with humps to control vehicle speeds. If the vehicle speed is measured using an instrumented vehicle for the development of a drive cycle, those data include the vehicle speed from all these sections of the road. When these data are used to construct a generic drive cycle for legislative testing, the drive cycle loses its details in terms of road geometry since the legislative tests assume zero gradient and a straight road. However, their effect on the increase in engine load and therefore emission levels cannot be neglected if the vehicle operating points lie outside the legislative controlled performance map of the engine [12], e.g. regions of overfuelling at high loads, etc. The generic approach derived in the present work uses all these details in conjunction with the measured tailpipeout emission levels for identification of the localized emission hot-spots.

\section{THE SCHEME OF APPROACH}

The approach used to derive spatial emissions data from the vehicle speed, time, and spatial geographical location data is explained below and illustrated in the flow diagram in Fig. 3:

1. Vehicle operating points on the engine map determine the levels of exhaust emissions from any vehicle. The vehicle operating points that are 


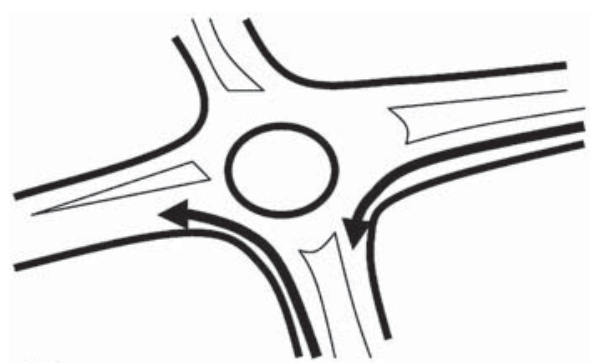

(a)

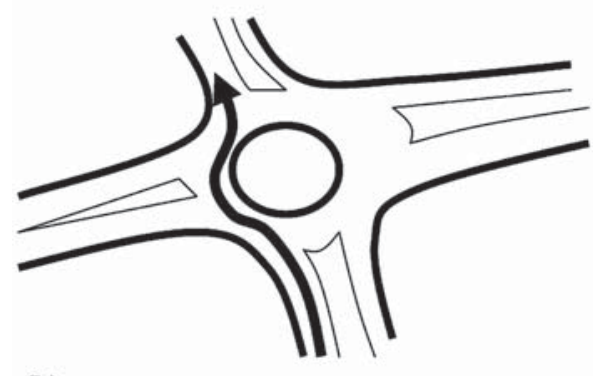

(b)

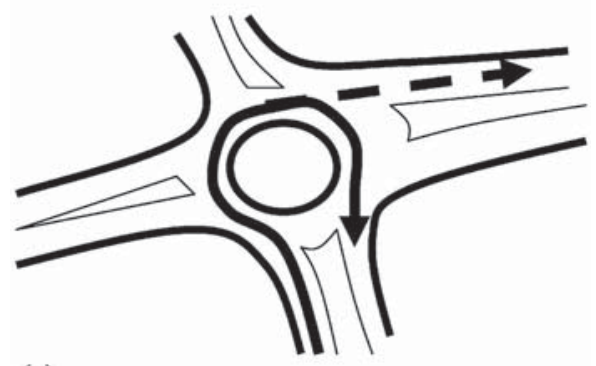

(c)

Fig. 2 Types of travel in negotiating roundabouts in the United Kingdom

simple to measure with conventionally instrumented vehicles are vehicle speed, gear shift history versus time and spatial geographical location of interest, landmarks, vertical road gradient, roundabouts, traffic islands, and speed humps versus time. Once these data sets are available for typical driving in a specific route, they can be used to construct a representative drive cycle.

2. The vehicle is then tested using this drive cycle on a chassis dynamometer. The emission levels are measured at the tailpipe-out location in a second-by-second mode.

3. These results are then plotted against the spatial distance travelled rather than the conventional timescale. For example, tailpipe-out CO levels in ppm are plotted against the distance travelled in $\mathrm{km}$ or $\mathrm{m}$. The information about the spatial

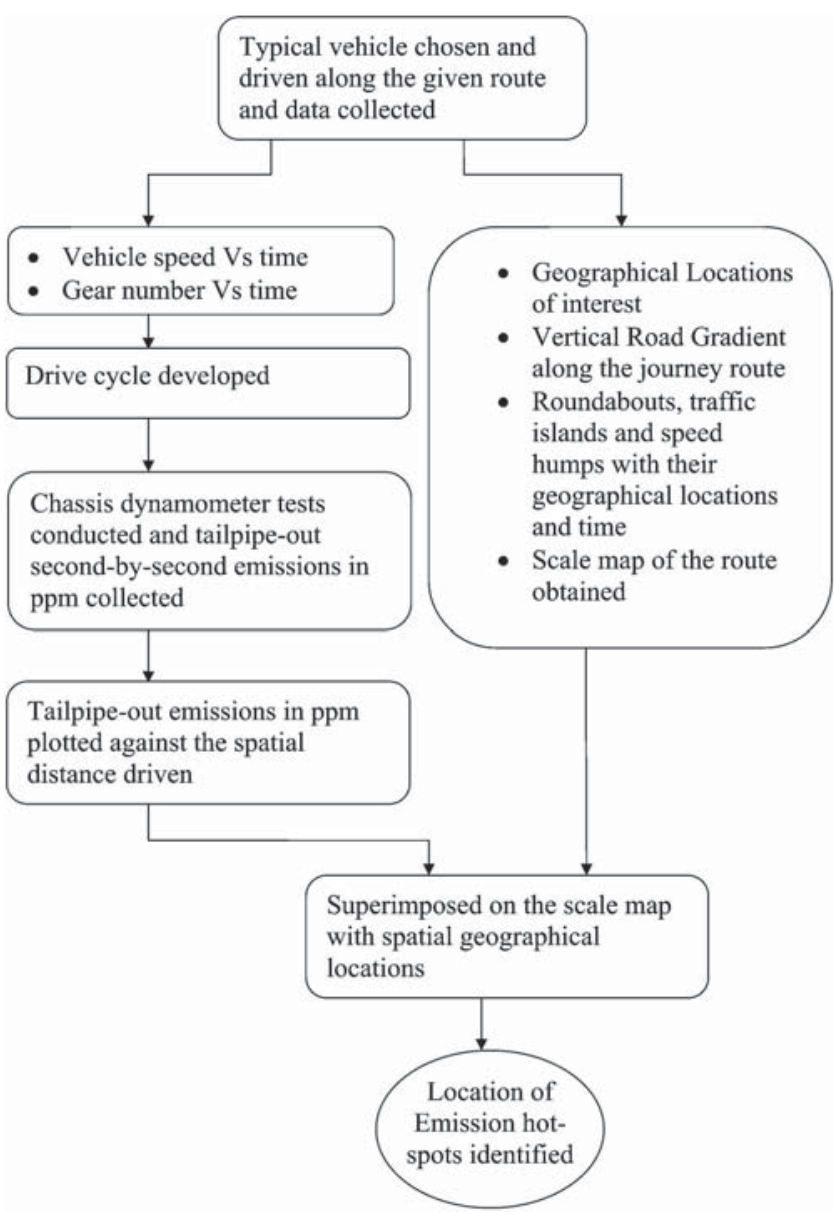

Fig. 3 Flowchart showing the scheme of approach

location of landmarks is then superimposed on the spatial emission plots. This yields valuable information about the location of the emission hot-spots created by the typical vehicle in that route.

This proposed approach is now demonstrated using a case study in the following sections.

\section{TYPICAL JOURNEY ROUTE AND EXPERIMENTS}

A journey route, which consisted of straight roads and roundabouts, was considered for the study for illustrative purposes. Vehicle speed and gear change pattern against time data constituting a representative drive cycle was obtained [16] for this experimental route for a typical driving pattern. In addition to the drive cycle data, the spatial geographic locations and landmarks of the route against 
the time was also collected for the purpose of analysis. Specifications of the experimental vehicle are given in Table 1. The experiments were conducted at Motor Industries Research Association (MIRA) using a chassis dynamometer test facility and emission monitoring systems. The drive cycle was used to test the same vehicle on a chassis dynamometer and tailpipe-out emission levels were collected. Emission measurements were carried out using CVS systems and also second-by-second trace modal measurements with the engine fully warmed up. These data were used for the spatial emission distribution analysis. The tailpipe-out emission values were then plotted against distance travelled and hence exact locations, rather than against the journey time. This enabled the identification of localized emission hot-spots in the journey route.

\section{SPATIAL EMISSION PROFILES}

\subsection{Spatial emission distribution along the straight road}

Two typical A-type straight roads shown in Figs 4 and 5 were used for the analysis. These roads are designated here as SR1 and SR2. The length of SR1 is $1 \mathrm{~km}$ and SR2 is $2.2 \mathrm{~km}$. The drive cycle data used for the test and the chassis dynamometer test results are shown in Figs 6 and 7. The tailpipe-out emissions and the spatial emission distribution for SR1 in Fig. 6 and SR2 in Fig. 7 show that the emission values are a function of the nature of driving. The weighted CO emission value from the CVS bag method for the entire route was found to be $2.62 \mathrm{~g} / \mathrm{km}$. If only weighted emissions are considered, straight roads

Table 1 Specifications of the experimental vehicle

\begin{tabular}{ll}
\hline Description & Value \\
\hline Vehicle & \\
$\quad$ Vehicle model year & 2001 \\
Emission certification & EURO-IV \\
Vehicle mass & $945 \mathrm{~kg}$ \\
Transmission & Manual \\
Engine & \\
Swept volume & 1.4 litre \\
Fuel and ignition & Gasoline, SI \\
Maximum power (bhp) & 100 at $6000 \mathrm{r} / \mathrm{min}$ \\
$\quad$ Maximum torque (N m) & 126 at $4400 \mathrm{r} / \mathrm{min}$ \\
Type of fuel injection system & Gasoline multipoint port injection system \\
Type of emissions control system & Three-way catalyst with lambda sensor \\
\hline
\end{tabular}

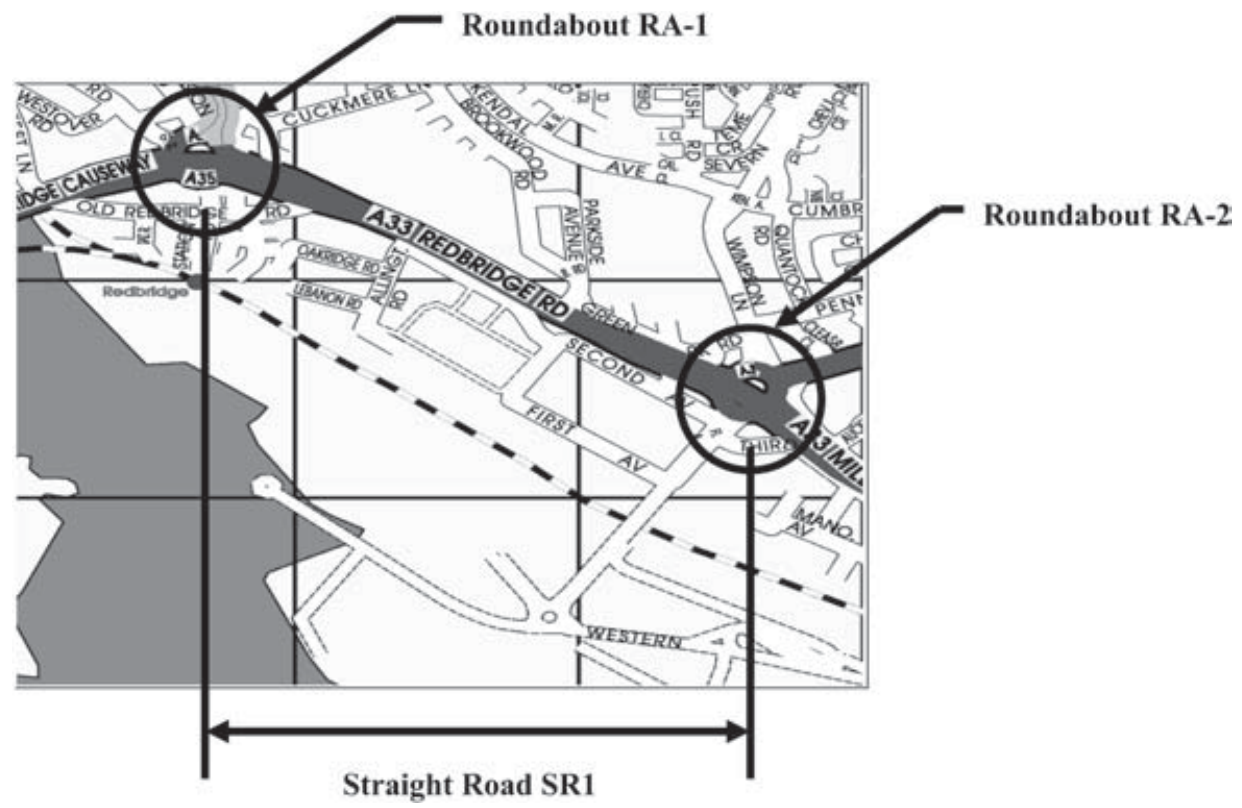

Fig. 4 Route map for spatial emission analysis includes one straight road SR1 and two roundabouts RA-1 and RA-2 [21] 


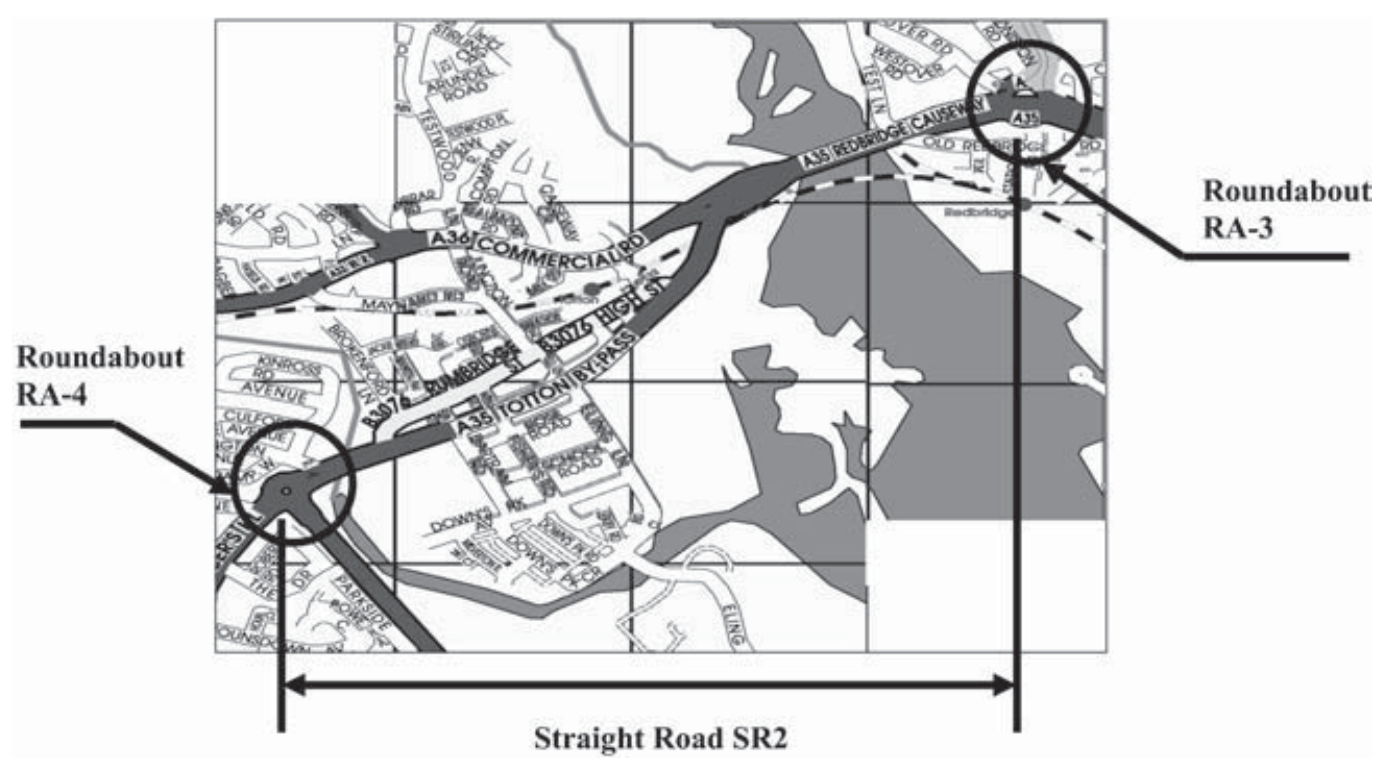

Fig. 5 Route map for spatial emission analysis includes one straight road SR2 and two roundabouts RA-3 and RA-4 [28]

SR1 and SR2 should have similar spatial emission profiles. In significant contrast, the spatial CO emission values vary from 2 to $4200 \mathrm{ppm}$ values for similar weighted emission values. Localized emission hotspots can be created when the vehicle tailpipe-out emission levels are significantly high (4200 ppm). These important details are lost when conventional weighted emission levels are used for a specific journey route. The vehicle used for the study was a relatively new Euro-IV vehicle with a running history of 1100 hours. Importantly, if this vehicle was fitted with an on-board diagnostic (OBD) system to measure the tailpipe-out CO levels and the measurements were taken when the spatial emission levels are high $(4200 \mathrm{ppm})$, it would have triggered its alarm, indicating that the OBD threshold value has been exceeded $(\sim 2150 \mathrm{ppm}$ or $\sim 1.9 \mathrm{~g} / \mathrm{km})$ and a failure of emission control equipments [24-26]. However, it may also be certified as a clean vehicle if the measurements are taken when the spatial emission levels are low (2 ppm). It was shown by Samuel et al. [12] that vehicles of this type produce significantly lower emission levels when vehicle operating points remain inside the legislative controlled engine performance map than when the vehicle operating points move outside the legislative controlled engine performance map.

\subsection{Roads with roundabouts and islands}

Horizontal road curvature due to the presence of roundabouts and traffic islands are a part of the journey route. The modes of travel while driving over the roundabouts can be divided into three types, as shown in Fig. 2. First and second modes represent driving past the roundabout, as shown in Figs 2(a) and (b). The third one, which allows the vehicle to take a U-turn as shown in Fig. 2(c), is significant in terms of the effect of road curvature on an increase in engine load. It has recently been identified by the Federal Highway Authorities [27] that horizontal road curvature increases engine load. Vehicle speed against time data of any drive cycle cannot be used to estimate this increase in engine load without specific details about the roundabouts. Only empirical relationships are available to include any correction for the effect of road curvature. However, the vehicle speed and gear shift pattern against time data, when used in conjunction with corresponding tailpipe-out emission data, can provide a significant amount of information in terms of the spatial emission distribution due to the inclusion of roundabouts in any journey route, since the presence of roundabouts dictates the driving pattern. The present work considered the first two modes of travel over the roundabouts for the spatial emission distribution.

The tailpipe-out emission levels over the roundabouts are shown in Figs 6 and 7. Waiting at the roundabouts for the traffic signal and leaving the roundabouts may produce up to $4200 \mathrm{ppm}$ of CO near the roundabouts as compared to only $20 \mathrm{ppm}$ for similar speeds when driving on straight roads.

\subsection{Variability in driving style}

The results shown in section 6.1 illustrate how localized emission hot-spots are created when 


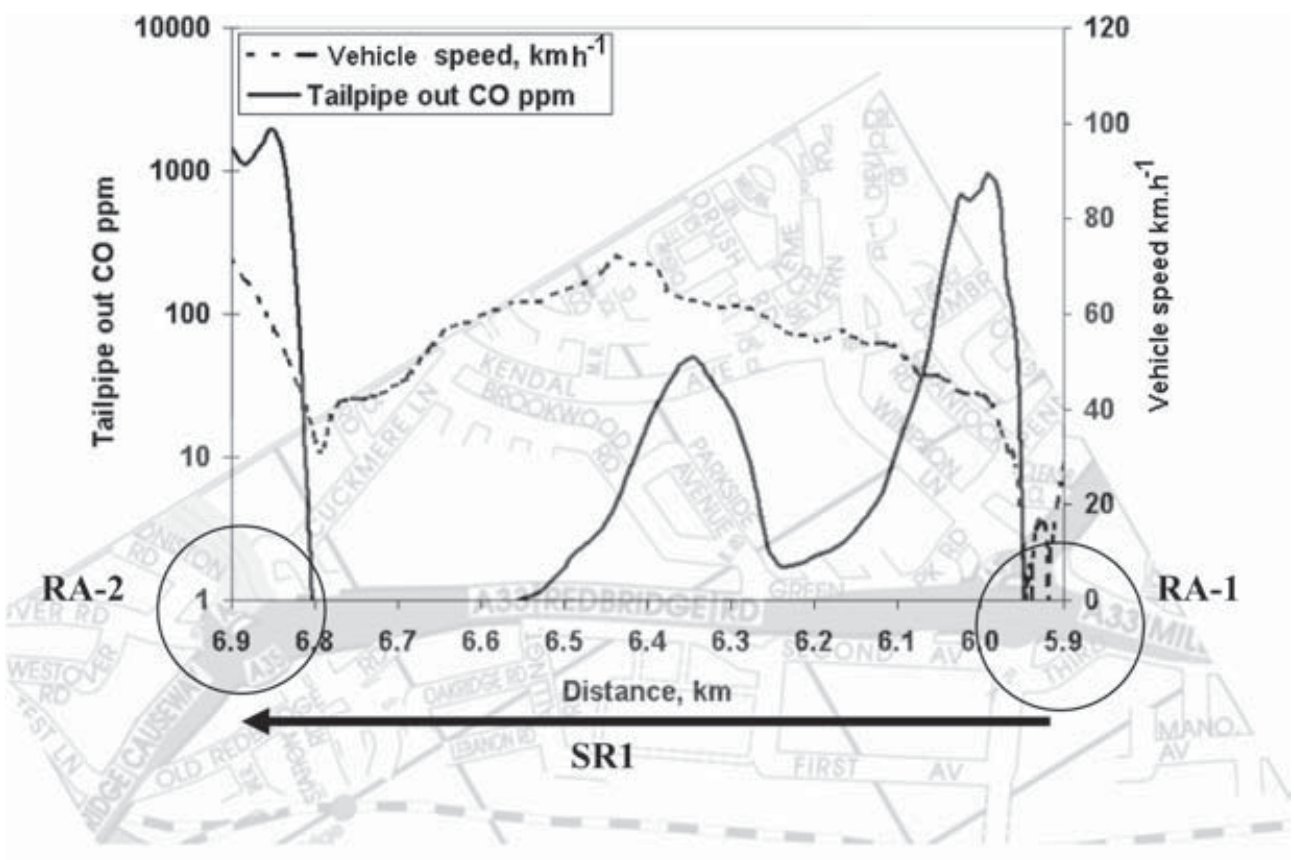

Segment 4: Journey from RA-1 and RA-2

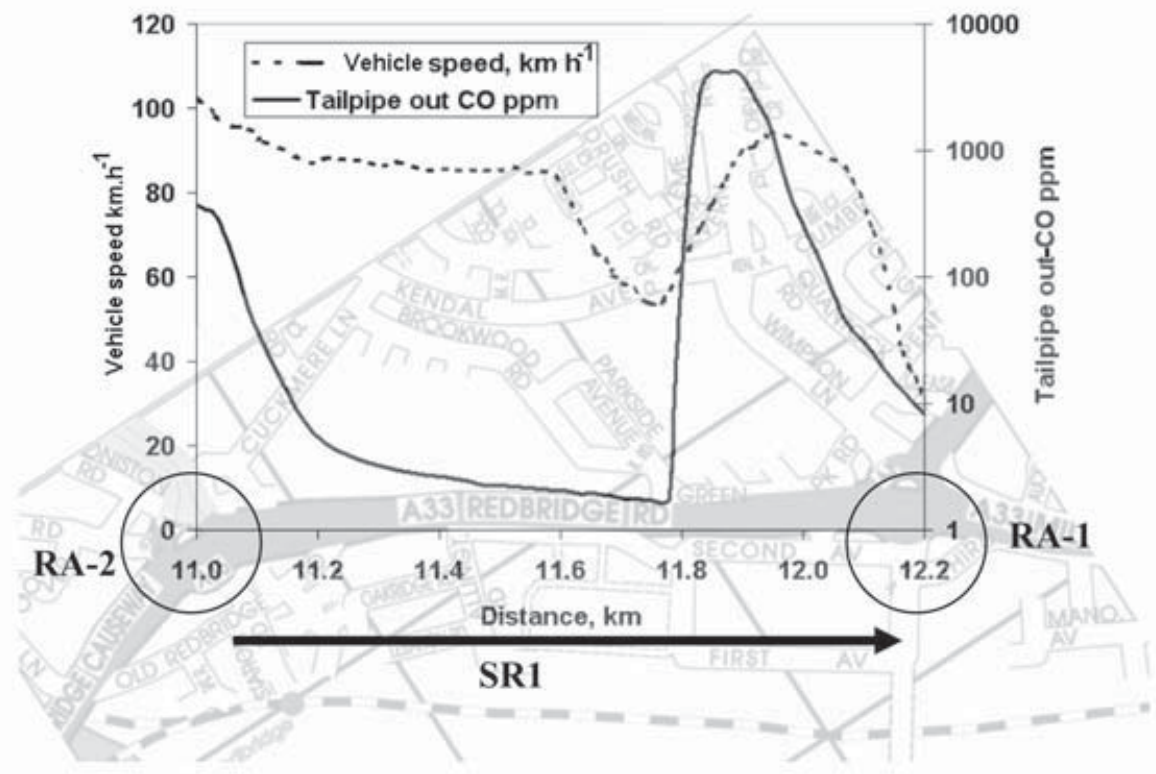

Journey from RA-2 to RA-1

Fig. 6 Spatial distribution of tailpipe-out CO for straight road segment SR1 and roundabouts RA-1 and RA-2

vehicles are driven aggressively. In considering the creation of localized emission hot-spots the fact should be acknowledged that there is a 'mixed bag' of 'drive cycles' $[\mathbf{1 8}, \mathbf{2 0}, \mathbf{2 9}]$ actually being driven and the likely drive cycle is a distribution of the various drive cycles. If the mix is skewed towards the passive driving style then the localized CO emission levels will be much less than suggested. However, if it is skewed towards the aggressive drive style, the localized CO emission levels will be very significant.

The experimental vehicle was driven on a chassis dynamometer for a passive driving style representing the driving in the routes given in Fig. 5. The results are shown in Fig. 8. The tailpipe CO levels were not 


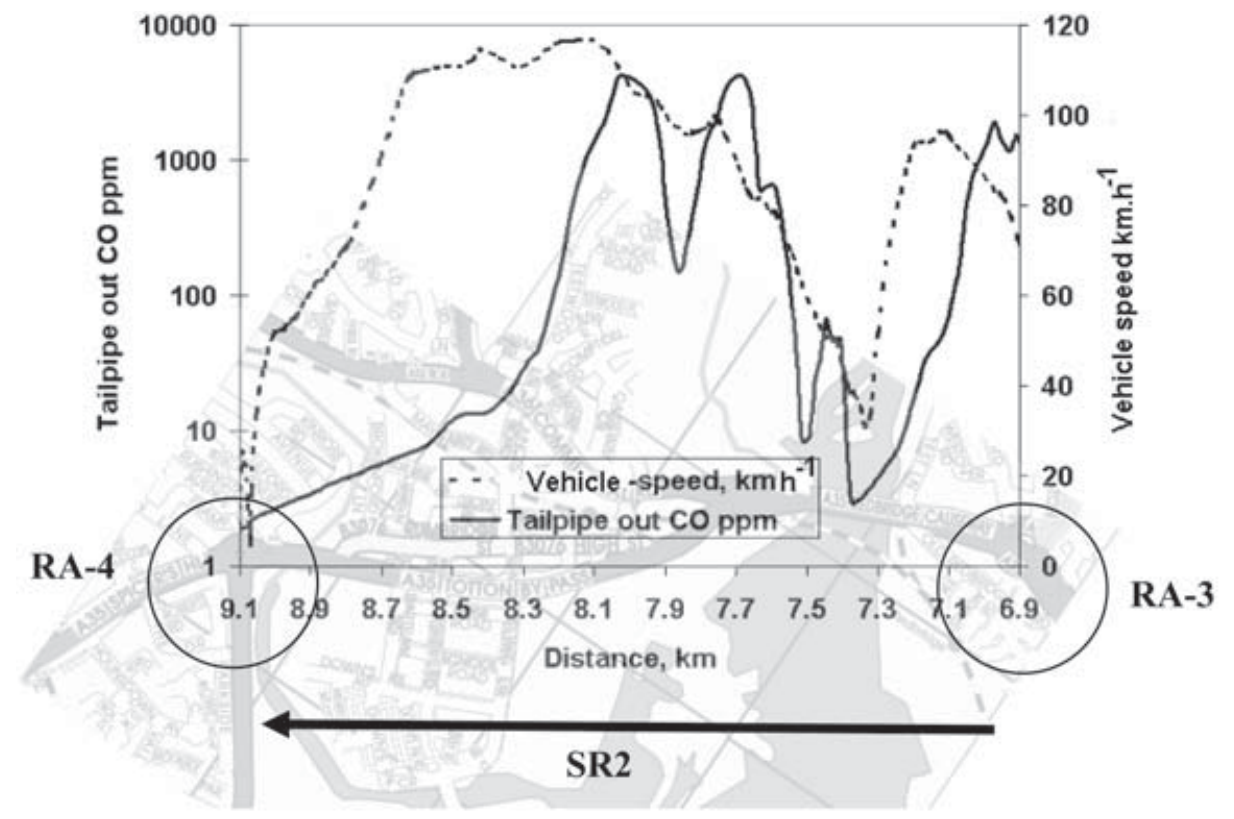

Journey from RA-3 to RA-4

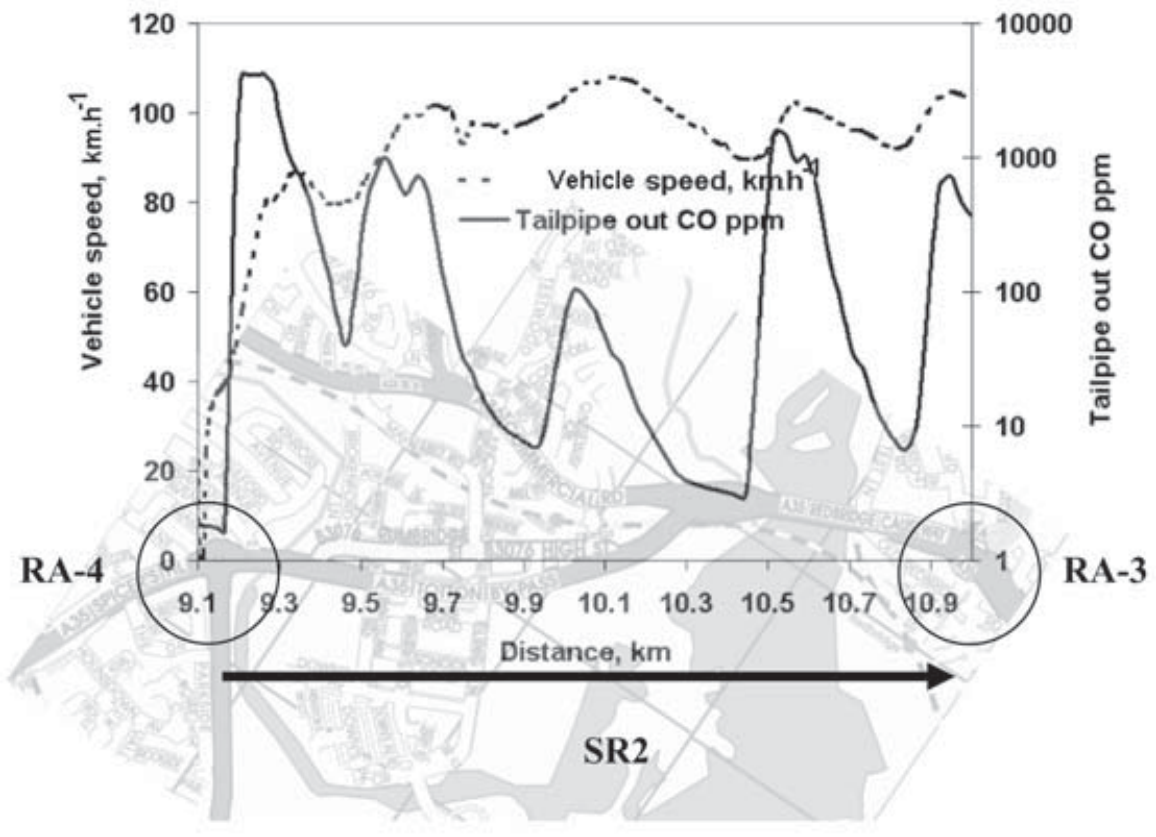

Journey from RA-4 to RA-3

Fig. 7 Spatial distribution of tailpipe-out CO for straight road segment SR2 and roundabouts RA-3 and RA-4

enough to create any localized emission hot-spots. This suggests that having a road network that will not allow drivers to drive aggressively or a road network that will allow drivers to drive smoothly without having to negotiate many speed humps might provide a way to reduce the possibility of creating localized CO emission hot-spots.

\section{APPLICATION}

One of the main applications of this approach is to help the road network planners and the local authorities to identify localized emission hot-spots in an area of interest, such as in the vicinity of schools and hospitals. For example, if there is a 


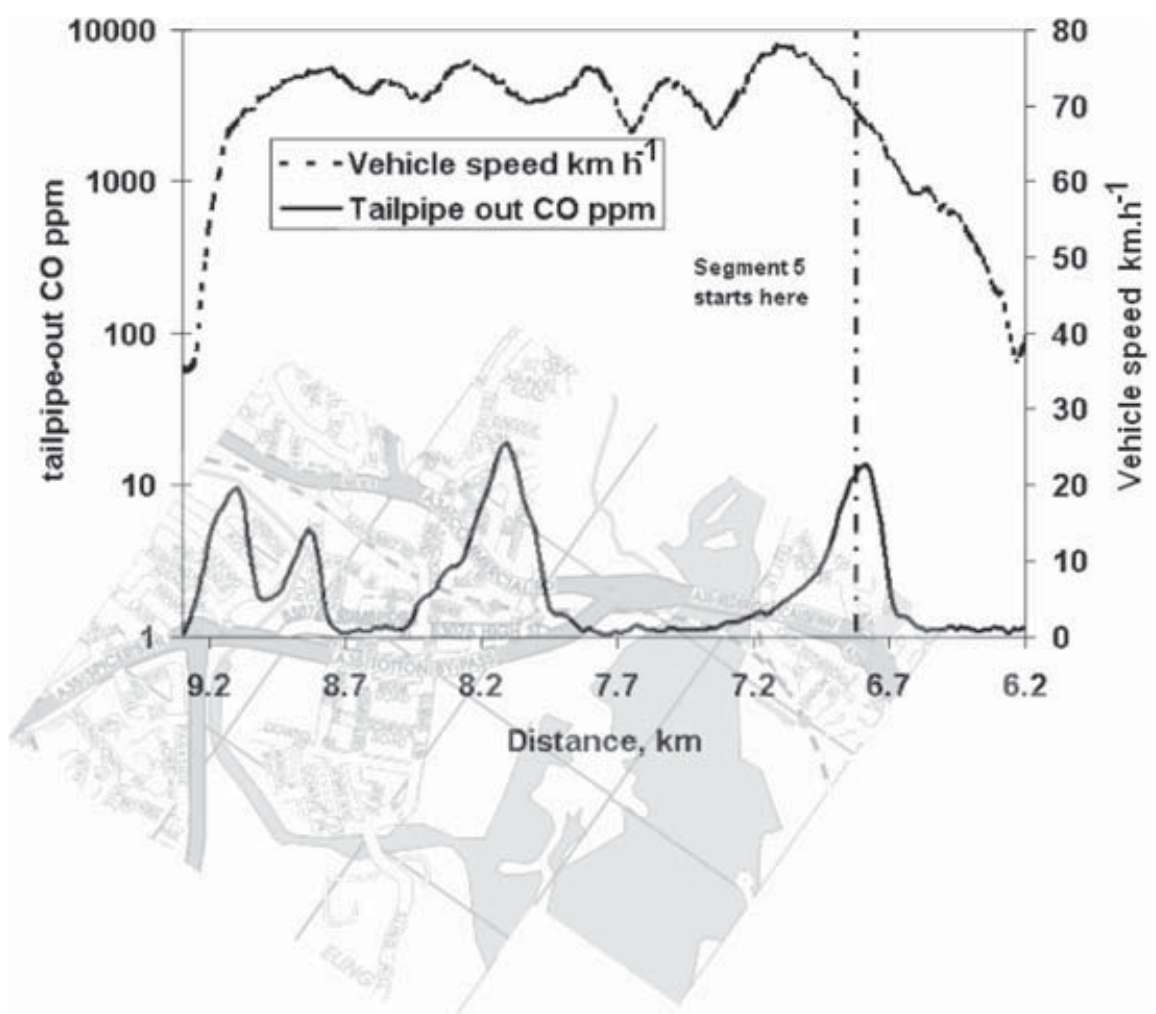

Fig. 8 Spatial distribution of tailpipe-out CO for straight road segment SR2 and roundabouts RA-3 and RA-4 when driven in the non-aggressive mode of driving

concern about highly localized CO emission hotspots near a school entrance due to humps and roundabouts, a typical vehicle that is regularly used in that area can be used to collect the vehicle speed, gear shift pattern against time data, and the spatial geographical data against time for the specific route of interest. This vehicle should then be tested on a chassis dynamometer and second-by-second emission levels in ppm measured. These results can then be plotted against the distance to predict the geographic location to identify the location of emission hot-spots. This will help to identify the impact of inclusion of roundabouts or speed humps etc. near the location of interest.

The effect of proposed roundabouts and traffic islands can be studied by creating temporary roundabouts and traffic islands and following the above method. This will identify the creation of new emission hot-spots.

\section{SCOPE OF THIS APPROACH}

The limitations of the proposed method can be grouped into two categories: firstly, errors arising if the representation of the drive cycle, which consists of the vehicle speed and gear shift pattern against time, is inadequate and, secondly, errors resulting from the inappropriate choice of the vehicle used for the analysis. The sensitivity of the approach can be improved by choosing the drive cycle that represents the extreme probable driving conditions in the specified route. In addition, the vehicle used can be from the category of vehicles certified for higher emission levels. If these two extreme conditions are met for deriving the spatial emission levels, the sensitivity in identifying emission hot-spots may be increased.

\section{CONCLUSION}

The present work showed that chassis dynamometer data can be used to identify localized emission hotspots over a specific vehicle route of interest. In addition, a spatial emission profile can be used to identify the condition of the vehicle and also to identify those crossing the gross polluting threshold margins. It is evident from the analysis that roadside CO concentration is not only a function of the number of vehicles per hour but also depends on the pattern of driving. Any vehicle can be a highemitting vehicle when the vehicle operating points remain outside the clean zone of the engine performance map. The roadside CO levels predicted by the 
DETR, which uses weighted emission levels and the national vehicle inventory to predict road-side CO levels, will significantly underestimate actual CO levels unless real-world drive cycle emissions are used for the prediction.

\section{ACKNOWLEDGEMENTS}

The authors would like to thank the AVERT Project team (funded by the EPSRC and DTI LINK through the Foresight Vehicle Programme) for their support and funding for this work.

\section{REFERENCES}

1 Stedman, J. R. and Linehan, E. B. A method for predicting roadside $\mathrm{CO}$ concentrations in the UK. DETR Report AEAT-5438, Issue 2, July 1999.

2 Murrells, T. P. UK Road Transport Emission Projections: the assumptions used and results of the 1997 National Atmospheric Emissions Inventory Base Projections; Web: http://www.aeat.com/netcen/ airqual/naei/roadproj/contents.html (date accessed 5 August 2004).

3 Angelino, E. Traffic induced air pollution in Milan city: a modeling study. In Urban Transport and the Environment of the 21st Century, Rhodes, Greece, September 1999.

4 Park, J. Y., Noland, R. B., and Polak, J. W. A microscopic model of air pollutant concentrations: comparisons of simulated results with measured and macroscopic estimates. In Annual Transport Research Board Meeting Publication, 2000.

5 Crabbe, H., Beaumont, R., and Norton, D. Assessment of air quality, emissions and management in a local urban environment. J. Environ. Monitoring and Assessment, 2000, 65(1/2), 435-442.

6 Ellis, K., McHugh, E., Carruthers, D., and Stidworthy, A. Comparison of ADMS-roads, CALINE4 and UK DMRB model predictions for roads. In 7th International Conference on Harmonization within Atmospheric Dispersion Modeling for Regulatory Purpose, Belgrate, Italy, May 2001.

7 Samuel, S. Transient vehicle emission levels and fuel economy in real-world driving conditions. $\mathrm{PhD}$ Thesis, Oxford Brookes University, 2004.

8 Mystkowski, C. and Khan, S. Estimating queue lengths using SIGNAL94, SYNCHRO3, TRANSFYT-7F, PASSER II-90 and CORSIM. In 78th Transportation Research Board Annual Meeting Publication, November 1998.

9 Ziad, Z., Wallace, C. E., and Lin, F.-B. Traffic analysis software tools. TRB Report E-CO14, September 2000.

10 McDonald, M., Wu, J., and Brackstone, M. Development of a fuzzy logic based microscopic motorway simulation model. In Proceedings of the ITSC 97 Conference, Boston, Massachusetts, 1997.
11 Fellendorf, M. and Vortisch, P. Validation of the microscopic traffic flow model VISSIM in different real-world situations. In VISSIM User Group Meeting Publications, Seattle, Washington, June 2001.

12 Samuel, S., Morrey, D., Fowkes, M., Taylor, D. H. C., Austin, L., Felstead, T., and Latham, S. The most significant vehicle operating parameter for realworld emission levels. SAE paper 2004-01-0636, 2004.

13 Kleeman, P. T. A fresh look at predicting carbon monoxide impacts at highway intersections. Report presented to TRB A1F03/A1F06 Joint Summer Meeting, Ann Arbor, Michigan, 1998.

14 Kågeson, P. Cycle beating and EU-Test cycle for cars. European Federation for Transport and Environment Report T\&E 98/3, Brussels, Belgium, November 1998.

15 Fernandez, P. C. and Long, J. R. Assessment of commuting under grade and ramp metering: preliminary on-road emission findings. In World Car Congress, University of California Riverside, January 1996.

16 Frey, C. H., Rouphail, N., Unal, A., and Colyer, J. Emissions and traffic control: an empirical approach. In Proceedings of CRC On-Road Vehicle Emissions Workshop, San Diego, California, March 2000.

17 Yu, L. Effects of high emitter vehicle on the on-road vehicle emission modeling. Center for Transportation Training Research, Texas Southern University, Report SWUTC/00/467600-1, October 2000.

18 Samuel, S., Morrey, D., Fowkes, M., Taylor, D. H. C., Austin, L., Fesltead, T., and Latham, S. Real-world fuel economy and emission levels of a typical Euro-IV passenger vehicle. Proc. Instn Mech. Engrs, Part D: J. Automobile Engineering, 2005, 219(D6), 833-842.

19 Felstead, T., Marsden, G., and McDonald, M. AVERT - developing a drive cycle to illustrate driving conditions in Southampton. AVERT Project Working Paper by Transport Research Group, Southampton University, 2001.

20 Air quality: Oxford monitoring stations, AEAT; Website: http://www.aeat.co.uk/netcen/aqarchive/ oxford/monsites.html (accessed 3 August 2005).

21 Clifford, M. J., Clarke, R., and Riffat, S. B. Drivers' exposure to carbon monoxide in Nottingham, UK. Atmospheric Environ., 1997, 31(7), 1003-1009.

22 Petersen, W. B. and Allen, R. Carbon monoxide exposures to Los Angelos area commuters. J. Air Pollution Control Ass., August 1982, 32(8), 826-833.

23 Chan, C. C., Ozkaynak, H., Spendgler, J. D., and Sheldon, L. Driver exposure to volatile organic compounds, $\mathrm{CO}$, ozone, and $\mathrm{NO}_{2}$, under different driving conditions. Environ. Sci. Technol., 1991, 25(5), 964-972.

24 Crookell, A. and Sinclair, P. Remote analysis of motor vehicle exhaust: the elusive emission factor. In 3rd International Conference on Urban Air Quality, Measurement Modeling and Management, Loutraki, Greece, 19-23 March 2001. 
25 Crookell, A. Consultation paper on requirements for remote sensing devices for gaseous emission monitoring - a European perspective, funded by European Commission's Competitive and Sustainable Growth Programme, REVEAL-1999-RD-0657, 13 July 2000.

26 Samaras, Z. Impact assessment/on board diagnostic (OBD) systems for passenger cars. Draft Final Report, Report 0409, for European Commission DG ENTR use, Laboratory of Applied Thermodynamics, University of Thessaloniki, Greece 3 July 2004.

27 Highway effects on vehicle performance. Federal Highway Administration, US Department of Transport, FHWA Report FHWA-RD-00-164, 2001.

28 Streetmap for Southampton road map and aerial view; www.streetmap.co.uk (accessed September 2002).

29 De Peter, H. and Keller, M. Real-world driving cycles for emission measurements: ARTEMIS and Swiss cycles. BUWAL Report 255, Swiss Agency for Environment, Forests and Landscape, 17 March 2001.
30 Van Mierlo, J., Maggetto, G., Van de Burgwal, E., and Gense, R. Driving style and traffic measures influence on vehicle emissions and fuel consumption.

\section{APPENDIX}

\section{Notation}

CO carbon monoxide

CVS constant volume sampling

DEFRA Department for Environment, Food and Rural Affairs

DETR Department of Environment, Transport and the Regions

MIRA Motor Industries Research Association

NAEI National Atmospheric Emission Inventory

OBD on-board diagnostic 